\title{
O ADOLESCENTE AUTOR DE OFENSA SEXUAL: DA DENÚNCIA À RESPONSABILIZAÇÃO JURÍDICA
}

Kárita Rachel Pedroso Bastos

Secretaria de Estado de Justiça e Cidadania do Distrito Federal Universidade de Brasilia

Liana Fortunato Costa

Universidade de Brasilia

\section{RESUMO}

Este artigo analisa o processo de responsabilização jurídica de adolescentes que cometeram ofensa sexual. Trata-se de pesquisa documental, contendo 223 processos judiciais de adolescentes denunciados formalmente por cometerem ofensa sexual, entre 2013 e 2015, no Distrito Federal. As informações foram organizadas num banco de dados e as análises estatísticas de frequência efetuadas pelo programa estatístico IBM SPSS Statistics, versão 24. Identificou-se que $40,3 \%$ dos adolescentes envolvidos tiveram processos arquivados ou extintos, seguidos de $21,3 \%$ que receberam a remissão. Quanto à responsabilização, 35,3\% dos adolescentes receberam medida socioeducativa, sendo priorizadas as medidas de meio aberto. Destes, 67,5\% conseguiram cumprir a medida socioeducativa. De um lado, a pesquisa confirmou a morosidade e ampla margem de discricionariedade dos juízes em relação à responsabilização do adolescente ofensor sexual. De outro, a prevalência das medidas de meio aberto traz a possibilidade de uma responsabilização potencialmente mais educativa.

Palavras-chave: adolescente; ofensa sexual; responsabilização; medidas socioeducativas. 


\section{THE ADOLESCENT AUTHOR OF SEXUAL OFFENSE: FROM DENUNCIATION TO LEGAL ACCOUNTABILITY}

\section{ABSTRACT}

This article analyses the process of legal liability of adolescents who committed sexual offenses. It is a documentary research, with 223 lawsuits of adolescents denounced for committing sexual offense, between 2013 and 2015, in Federal District. Informations were organized in a database and statistical frequency analyzes were performed using the IBM SPSS Statistics software, version 24. It was found that $40.3 \%$ of the adolescents involved had lawsuits filed or extinguished, followed by $21.3 \%$ who received the remission. Regarding accountability, $35.3 \%$ of the adolescents received socio-educational measures, with priority being given to noncustodial sanctions. Of these, $67.5 \%$ were able to comply with the socioeducational measure. On one side, the research confirmed the slowness and wide margin of discretion of judges regarding the accountability of the adolescent sexual offender. On the other side, the prevalence of noncustodial sanctions measures makes the possibility of more educational potentially accountability.

Keywords: adolescent; sexual offense; accountability; socio-educational measures.

\section{EL ADOLESCENTE AUTOR DE OFENSA SEXUAL: DE LA DENUNCIA A LA RESPONSABILIDAD LEGAL}

\section{RESUMEN}

Este artículo analiza el proceso de responsabilidad legal de los adolescentes que cometieron ofensas sexuales. Es una investigación documental, con 223 procesos de adolescentes denunciadas por cometer ofensas sexuales, entre 2013 y 2015, en el Distrito Federal. La información se organizó en una base de datos y los análisis estadísticos de frecuencia se realizaron utilizando el software IBM SPSS Statistics. Se descubrió que el 40,3\% de los adolescentes involucrados tenían procesos archivados o extinguidos, seguido por el $21.3 \%$ que recibió la remisión. Con respecto a la responsabilidad, el 35,3\% de los adolescentes recibió medidas socioeducativas, dando prioridad a las medidas de ambiente abierto. De estos, el $67,5 \%$ completó la medida socioeducativa. La investigación confirmó la lentitud y el amplio margen de discreción de los jueces con respecto a la responsabilidad del adolescente. La prevalencia de las medidas de ambiente abierto brinda la posibilidad de una mayor responsabilidad educativa.

Palabras clave: adolescente; ofensa sexual; responsabilidad medidas socioeducativas. 


\section{INTRODUÇÃO}

O presente artigo situa-se na interface entre Direito, Psicologia e Serviço Social e tem como objetivo analisar o processo de responsabilização jurídica do adolescente que cometeu ato infracional análogo ao crime de estupro, denominado aqui de adolescente autor de ofensa sexual. Por meio do estudo de 223 processos judiciais de adolescentes denunciados formalmente por cometerem ofensa sexual, no período de 2013 a 2015, no Distrito Federal, buscou-se conhecer a trajetória jurídica desse adolescente e como ocorre a sua responsabilização em caso de comprovação da conduta infracional. Conforme Penso, Conceição e Costa (2018), o contexto jurídico apresenta uma complexidade social no âmbito dos julgamentos que necessita incorporar noções e conceitos de outras áreas para uma melhor análise da realidade social, tão permeada de contradições. Dessa forma, é importante que a dimensão reguladora e normativa do Direito, se articule à dimensão compreensiva do comportamento humano da Psicologia (Penso et al., 2018) e à dimensão social de defesa da cidadania e efetivação dos direitos do Serviço Social (Conselho Federal de Serviço Social [CFESS], 2013), construindo novos sentidos para as relações sociais, com reflexão e interpretação crítica das demandas jurídicas (Fávero, 2013).

\section{MODELO DE RESPONSABILIZAÇÃO DEFINIDO PELO ESTATUTO DA CRIANÇA E DO ADOLESCENTE}

A Doutrina de Proteção Integral estabelecida pelo Estatuto da Criança e do Adolescente (ECA) definiu como forma de tratamento judicial ao adolescente autor de ato infracional, um modelo de responsabilidade que não se confunde com o Direito Penal Contemporâneo, mesmo que seja próximo em suas grandes linhas. Esse modelo, de natureza garantista, inspirado por princípios que limitam o poder sancionatório do Estado, assegura que as sanções impostas não sejam eminentemente retributivas, mas essencialmente educativas, reconhecendo que o adolescente está em fase peculiar de desenvolvimento e em processo de construção de suas potencialidades adultas e, por isso, a aplicação de uma sanção deve ser diferente daquela aplicada ao adulto, priorizando o aspecto educativo ao punitivo (Saraiva, 2017). Frasseto, Guará, Botarellii e Barone (2012) afirmam que a ideia de responsabilização do adolescente autor de ato infracional utilizada no âmbito jurídico está associada à natureza da resposta do Estado ao adolescente que comete infração, ou seja, a imposição de deveres decorrentes da prática do ato infracional.

Nessa lógica, a inimputabilidade, instituída pela Constituição Federal de 1988 aos menores de 18 anos não é sinônimo de impunidade. O ECA estabelece, nos casos de comprovação da prática de ato infracional, um sistema de responsabilização baseado na aplicação de medidas socioeducativas. As medidas socioeducativas são destinadas aos adolescentes de 12 a 18 anos. Para os menores de 12 anos que cometeram algum ato infracional corresponderão às medidas protetivas, 
conforme artigo 101 da Lei n 8.069 do ECA (Presidência da República, 1990). A medida socioeducativa deverá ser imputada de acordo com a capacidade do adolescente de cumpri-la e conforme a gravidade do ato, tendo como objetivos a "responsabilização do adolescente quanto às consequências lesivas do ato infracional, sempre que possível incentivando a sua reparação"; "a integração social do adolescente e a garantia de seus direitos individuais e sociais"; a "desaprovação da conduta infracional" (Presidência da República, 1990, 2012).

Em seu artigo 112, o ECA estabelece que podem ser aplicadas seis medidas socioeducativas: advertência; obrigação de reparar o dano; prestação de serviços à comunidade; liberdade assistida; inserção em regime de semiliberdade; e internação em estabelecimento educacional. A aplicação das medidas deve ter como princípios a brevidade, a excepcionalidade e o respeito à condição peculiar da pessoa em desenvolvimento. A internação, medida considerada mais severa, só deve ser aplicada em último caso por privar o adolescente da liberdade, um dos seus direitos fundamentais.

Em que pese à importância do paradigma da Doutrina de Proteção Integral, que fundamenta o ECA, autores na área do Direito Penal Juvenil apontam para a necessidade de algumas reformas do estatuto. Reconhece-se que o ECA tem sido exitoso em relação à proteção, mas está muito longe do ideal no se refere à responsabilização do adolescente pelo cometimento de ato infracional. Uma das maiores críticas envolve a ampla margem de discricionariedade deixada nas mãos dos juízes, promotores de justiça, defensores públicos ou advogados (Andrade \& Machado, 2017). Pesquisa realizada por Minahim (2010), em diversos estados brasileiros, constatou que o ECA vem sendo interpretado de forma bastante heterogênea pela jurisdição de primeiro grau. Conforme resultados da pesquisa, a celeridade processual acaba sendo preponderante ao devido processo legal; não há confrontação com testemunhas; a participação da defesa técnica, por intermédio da Defensoria Pública, é inexpressiva; a atuação conjunta do Juiz, Ministério Público e Defensor Público confere à audiência uma aparência de "junta administrativa" e não de atores protagonistas num procedimento onde há o contraditório; a medida socioeducativa de internação é sistematicamente imposta com baixa fundamentação legal; dentre outras situações em que o ECA não prevê detalhes relativos ao procedimento de apuração do ato infracional cometido por adolescente.

É nesse contexto, de crise de interpretação e implementação do ECA (Mendez, 2000), que se pretende refletir sobre a responsabilização do adolescente que comete ato infracional equivalente ao estupro. Nos últimos anos a legislação brasileira tem ampliado o entendimento dos crimes contra a dignidade sexual. $\mathrm{O}$ artigo 213 do Código Penal, alterado pela Lei 12.015/2009, considera estupro o ato de "constranger alguém, mediante violência ou grave ameaça, a ter conjunção carnal ou a praticar ou permitir que com ele se pratique outro ato libidinoso" e o artigo 217-A considera estupro de vulnerável "ter conjunção carnal ou praticar ato libidinoso com menor de 14 anos", incorrendo na mesma pena 
"quem pratica ações descritas no caput com alguém que, por enfermidade ou deficiência mental, não tem o necessário discernimento para a prática do ato, ou que, por qualquer outra causa, não pode oferecer resistência" (Presidência da República, 2009). Recentemente, a Lei 13.718 de 2018 também alterou os artigos 215 e 218 do Código Penal, tipificando como crime a importunação sexual, considerada como "praticar contra alguém e sem a sua anuência ato libidinoso com o objetivo de satisfazer a própria lascívia ou a de terceiro", assim como a oferta, troca, publicação ou divulgação nos meios de comunicação de cenas de estupro ou estupro de vulnerável ou que induza a sua prática, bem como cenas de sexo, nudez ou pornografia sem o consentimento da vítima (Presidência da República, 2018).

Considerado um grave problema de saúde pública e de violação dos direitos humanos, a violência sexual provoca sérias consequências no desenvolvimento psicológico e emocional das vítimas (World Health Organization, 2002). É também uma problemática social complexa que exige a atuação dos diferentes setores sociais e das diversas políticas públicas para o acompanhamento das vítimas, dos ofensores e de seus familiares. Soma-se a isso, a necessidade do Estado, por meio do Sistema de Justiça, dar uma resposta a quem comete o estupro. Estudos apontam que a transgressão/infração na adolescência deve ser compreendida como um sintoma, uma denúncia de que algo não está bem, um pedido de socorro (Penso, Conceição, Costa, \& Carreteiro, 2012). Assim, compreender o que 0 adolescente está comunicando com seus atos transgressivos, o sofrimento imbuído nesses atos, advindo do sofrimento vivenciado também pela família, bem como entender o contexto econômico e social no qual está inserido, exige uma articulação das dimensões reguladora, compreensiva e social, bem como construção de um conhecimento interdisciplinar que seja referência para as decisões judiciais.

\section{O ADOLESCENTE AUTOR DE OFENSA SEXUAL}

O termo ofensa sexual tem sido especialmente utilizado na literatura estrangeira (Domingues, 2016), de forma equivalente a palavra abuso sexual, que no Brasil, é utilizada cientificamente em referência a situações de violência sexual contra crianças e adolescentes, indicando desnível de poder na relação entre duas pessoas (Padilha \& Filho, 2016). Porém o termo ofensa sexual está voltado principalmente para a pessoa que praticou o ato, ou seja, o ofensor, adulto ou adolescente, que tenha sido julgado e condenado por uma ofensa sexual. Nessa perspectiva, considera-se ofensa sexual todo ato de cunho sexual, onde há violência física e/ou verbal, além de estratégias de manipulação e coerção envolvendo relações de dominação que são estabelecidas entre o agressor e sua vítima (Padilha \& Filho, 2016). Tais atividades podem ocorrer de diversas formas como contato físico (com ou sem penetração), exposição a conteúdos eróticos ou pornográficos e abuso sexual para fins lucrativos (Santos \& Dell'Aglio, 2013), incluindo assim o estupro e a importunação sexual, conforme regulamentado em lei. 
No Brasil, poucos são os estudos sobre adolescentes que cometem ofensa sexual, tanto no que se refere a dados estatísticos sobre denúncias e encaminhamentos feitos, quanto ao perfil do adolescente, à trajetória de vida (Costa, Junqueira, Ribeiro, \& Menezes, 2011; Instituto de Pesquisas Econômicas e Aplicadas [IPEA], 2018; Pincolini \& Hutz, 2014) e à responsabilização jurídica com aplicação das medidas socioeducativas nos casos de comprovação da ofensa sexual. Worling e Langton (2015) apontam que nos Estados Unidos e no Canadá a violência sexual vem sendo cada vez mais cometida por adolescentes. Segundo Pullman, Leroux e Seto (2014), na América do Norte, entre 14\% a 18\% das prisões, por ofensa sexual, são cometidas por jovens abaixo de 18 anos. Especificamente nos EUA, dos adolescentes com idades entre 12 e 17 anos, 33\% já foram vítimas de violência sexual e 20\% foram identificados como ofensores sexuais (Yeater, Lenberg, \& Bryan, 2012). Aproximadamente 50\% dos perpetradores de violência sexual referem que os primeiros atos de agressão sexual contra mulheres começaram na adolescência (Pullman \& Seto, 2012). Devido ao aumento de jovens que cometem ofensas sexuais, muitas políticas públicas têm sido implementadas, com o objetivo de reduzir tais estatísticas (Pullman et al., 2014).

Já no Brasil, o Atlas da Violência aponta que em 2016 foram registrados nas delegacias brasileiras 49.497 casos de estupro e 22.918 notificações dessa natureza no Sistema de Informação de Agravos de Notificação (SINAN) do Sistema Único de Saúde - SUS (IPEA, 2018). Apesar dos dados do SINAN serem aproximadamente metade daqueles registrados nas delegacias, a pesquisa identificou um aumento de $90,2 \%$ das notificações de violência sexual entre os anos de 2011 e 2016. No entanto, mesmo com a alta incidência, pode-se considerar que as duas bases de informações ainda não dão conta da dimensão real do problema. Estudos apontam que há uma grande subnotificação dos casos de violência sexual, que se deve em grande parte aos sentimentos de vergonha, medo e tolerância da vítima, medo de dissolução da família, da insistência dos tribunais por regras estritas de evidência, receio dos inúmeros questionamentos e interrogatórios ao longo do processo judicial, além da existência de tabus culturais, favorecendo a manutenção da violência em segredo por anos (Ministério da Saúde, 2018).

A despeito da relevância dos dados, o Atlas da Violência não identifica os ofensores por faixa etária, impossibilitando o conhecimento do número de ofensores adolescentes. Em relação às vítimas, houve predominância de crianças de até 13 anos (50,9\%) e adolescentes de 14 a 17 anos (17,5\%). Acerca da relação entre o ofensor e a vítima, também em 2016, observou-se que $31,13 \%$ dos casos contra criança são perpetrados por familiares próximos (pais, irmãos, padrastos). Já na fase adolescente e adulta, prevalecem casos com ofensor desconhecido, $32,5 \%$ e 52,52\% respectivamente, seguido de ofensores que são amigos ou conhecidos das vítimas, 26,09\% e 18,82\% (IPEA, 2018).

Em relação à responsabilização dos autores da ofensa sexual, dados do Levantamento Nacional de Informações Penitenciárias (Ministério da Justiça e 
Segurança Pública, 2017) mostram que em 2016, 11.609 pessoas estavam presas por estupro, sendo 11.540 homens e 69 mulheres. Além disso, 6079 pessoas estavam presas por estupro de vulnerável, sendo 5977 homens e 95 mulheres. Quanto aos adolescentes ofensores sexuais, o Levantamento Anual Sistema Nacional de Atendimento Socioeducativo (SINASE) de 2016, do Ministério de Direitos Humanos (Ministério dos Direitos Humanos, 2018) identificou um total de 26.450 adolescentes e jovens (12 a 21 anos) em atendimento socioeducativo nas unidades voltadas à restrição e privação de liberdade (internação, internação provisória e semiliberdade) em todo o Brasil. Destes, 321 estavam cumprindo medida socioeducativa por estupro, correspondendo a $1,2 \%$ dos casos. No entanto, além da subnotificação, há dificuldade de encontrar dados sistematizados e oficiais que demonstrem quantos casos notificados chegaram a responsabilizar os acusados.

Nesse cenário, é possível observar que, mesmo diante da alta incidência da violência sexual, existe uma lacuna em relação aos dados referentes à responsabilização, seja de adultos ou adolescentes ofensores sexuais. Costa e Santos (2013) destacam que, apesar de a responsabilização do autor da violência sexual se apresentar como uma importante forma de controle social, somente manter o ofensor preso não é suficiente para a prevenção da reincidência. Em geral, o ofensor precisa de atendimento psicológico especializado e acompanhamento. Especialmente com adolescentes, uma responsabilização adequada e um acompanhamento eficaz, além de preventivo, trazem importantes contribuições no âmbito social. Além disso, Domingues (2016) ressalta que uma visão do adolescente em processo de desenvolvimento auxilia a construção de um plano interventivo adequado e compatível à sua idade, uma vez que os adolescentes respondem mais ao tratamento que aqueles que já atingiram a fase adulta. Diante do exposto, este artigo objetiva analisar o processo de responsabilização do adolescente autor de ofensa sexual, principalmente com relação à trajetória do adolescente ao longo do processo de apuração da ofensa sexual e à atuação do Sistema de Justiça na aplicação das medidas socioeducativas.

\section{MÉTODO}

Para analisar a trajetória do adolescente ofensor sexual e como ocorre à responsabilização jurídica, realizou-se pesquisa documental junto aos processos judiciais de adolescentes, do sexo masculino, denunciados por cometerem ofensa sexual/estupro, no período de 2013 a 2015, no Distrito Federal.

Ao estudar a trajetória de responsabilização do adolescente que cometeu ofensa sexual, considerou-se importante identificar os trâmites judiciais que envolvem desde a denúncia à aplicação da medida socioeducativa, clarificando os encaminhamentos realizados pelo Sistema de Justiça. Ressalta-se que, para o direito penal, a denúncia é a peça de acusação que inicia o processo, feito pelo representante do Ministério Púbico e que leva ao conhecimento do juiz a 
ocorrência do crime. No entanto, considerou-se nesse artigo a denúncia entendida no senso comum, enquanto o momento em que a vítima ou responsável faz a queixa da violência sofrida para as autoridades policiais ou órgãos protetivos, uma vez que esse é um momento decisivo na organização familiar da vítima e também do adolescente ofensor.

\section{CONTEXTO}

O contexto da pesquisa é o de violência sexual perpetrada por adolescentes e o processo de responsabilização jurídica, nos casos de comprovação da conduta infracional. Tal contexto envolve diversos atores, dentre eles a família, o Sistema de Justiça e os órgãos de execução das medidas socioeducativas. Conforme Tribunal de Justiça do Distrito Federal e dos Territórios (2020), no Distrito Federal (DF) o Sistema Judiciário Infantojuvenil é composto pelas seguintes unidades:

- Vara Regional de Atos Infracionais da Infância e da Juventude do DF - VRAIJ: tem competência restrita a apuração dos atos infracionais, cuja área de jurisdição abrange as Regiões Administrativas de Samambaia, Recanto das Emas, Ceilândia, Taguatinga, Águas Claras, Brazlândia e Vicente Pires;

- Vara da Infância e da Juventude do DF - VIJ: tem sob sua responsabilidade todas as questões cíveis de infância e de juventude com jurisdição em todo o DF. Compete ainda à VIJ apurar os atos infracionais que não sejam da jurisdição da Vara Regional de Atos Infracionais da Infância e da Juventude do DF;

- Vara de Execução de Medidas Socioeducativas do DF - VEMSE: tem como competência a execução, o acompanhamento e a avaliação das medidas socioeducativas previstas nos incisos I a VI do artigo 112 do ECA, em todo DF. Além disso, é responsável por inspecionar os estabelecimentos e os órgãos encarregados do cumprimento das medidas socioeducativas e promover ações para o aprimoramento do sistema de execução dessas medidas;

- Núcleo de Apoio ao Atendimento Integrado Judicial ao Adolescente em Conflito com a Lei - NAIJUD: apoia a Vara da Infância e da Juventude, a Vara Regional de Atos Infracionais da Infância e da Juventude e a Vara de Execução de Medidas Socioeducativas, realizando com celeridade e eficiência o atendimento aos adolescentes apreendidos em flagrante pelas delegacias da Criança e do Adolescente do DF.

Atualmente a efetivação das medidas socioeducativas está sob a responsabilidade da Secretaria de Estado de Justiça e Cidadania do Governo do DF, por meio da Subsecretaria do Sistema Socioeducativo - SUBSIS. Para o cumprimento, a SUBSIS conta com 15 Unidades de Meio Aberto - UAMA, responsáveis pela execução da Prestação de Serviço à Comunidade - PSC e da Liberdade Assistida - LA; 05 Unidades de Semiliberdade e 07 Unidades de Internação, sendo uma a Unidade de Atendimento Inicial, vinculada ao Núcleo de Atendimento Integrado. 
O processo de apuração da ofensa sexual só é iniciado após a denúncia do fato, junto às Delegacias da Criança e do Adolescente do DF, gerando um Boletim de Ocorrência. Mesmo quando a denúncia é realizada primeiramente no Conselho Tutelar, este deve procurar a Delegacia da Criança e do Adolescente para abertura do boletim. Existem casos em que a vítima ou responsável buscam atendimento nos órgãos de saúde ou entram em contato com os canais de denúncia anônima, locais estes que também reportam o fato às delegacias para apuração. Geralmente nos Boletins de Ocorrência, o responsável pela vítima ou a própria vítima informam a data em que ocorreu a ofensa sexual ou a data na qual a família teve conhecimento do fato, denominada data da revelação da ofensa sexual (Padilha \& Filho, 2016). Tais informações são importantes para que se possa conhecer o tempo decorrido entre a revelação e a realização da denúncia nos órgãos competentes. Após investigação inicial, as delegacias encaminham os casos para a VIJ ou VRAIJ, conforme as áreas de abrangência. Em casos em que o adolescente é apreendido em flagrante, o processo é iniciado pelo juiz do NAIJUD que atua no Núcleo de Atendimento Integrado, onde o adolescente permanece por até vinte e quatro horas. Posteriormente o processo é encaminhado às respectivas Varas para prosseguimento da apuração. Com a finalização da apuração e publicação da sentença, os processos cujos adolescentes foram responsabilizados por meio de alguma medida socioeducativa são encaminhados à VEMSE para continuidade e acompanhamento da execução da medida, até que o adolescente seja oficialmente liberado.

\section{SELEÇÃO DOS PROCESSOS}

Para seleção dos processos, definiu-se como critérios de inclusão na pesquisa os processos já encerrados (sentenciados), cuja comunicação aos órgãos competentes (denúncia) ocorreu entre janeiro de 2013 a dezembro de 2015, com autores entre 12 e 17 anos, do sexo masculino, denunciados formalmente de cometerem ato infracional relativo a estupro/ofensa sexual. Foram excluídos os processos que ainda estavam em andamento, com data de comunicação aos órgãos competentes fora do período definido, os processos que não tinham identificação do ofensor ou com ofensor menor de 12 anos, além dos processos duplicados. Nos casos de adolescentes identificados com mais de um processo de estupro, priorizou-se aquele com data mais recente.

A VIJ e VRAIJ realizam a apuração do ato infracional de forma independente e não possuem um sistema de informação único capaz de identificar os adolescentes conforme ato infracional cometido em todo DF. Para identificação dos processos apurados pela VIJ, a própria Vara solicitou à Delegacia da Criança e do Adolescente um levantamento dos boletins de ocorrência decorrentes de violência sexual perpetrada por adolescentes de janeiro de 2013 a dezembro de 2015. A partir desse levantamento, buscou-se nominalmente os adolescentes no sistema de informação da VIJ, sendo identificados 70 processos sob a área de jurisdição do órgão. Já na VRAIJ, o levantamento dos adolescentes aconteceu 
através do Núcleo de Estatística, sendo possível identificar 153 processos conforme os critérios de inclusão. Ao todo foram então analisados os documentos de 223 processos referentes à ofensa sexual praticada por 253 adolescentes no período estudado, uma vez que em vários processos estiveram envolvidos enquanto ofensor mais de um adolescente. Ressalta-se, assim, que o universo estudado relaciona-se ao contexto jurídico, no qual os adolescentes foram investigados e receberam uma resposta do Sistema de Justiça, seja a responsabilização, a absolvição ou arquivamento do processo devido à falta de provas.

\section{INSTRUMENTO}

Para registro das informações, foi elaborado antecipadamente um instrumento específico, contendo questões relativas ao processo (período de apuração, sentença, aplicação de medida protetiva e/ou socioeducativa), características do adolescente acusado e família (idade do adolescente na data do fato, atos infracionais/processos anteriores, local de moradia, escolaridade, número de membros na família, responsável, renda familiar, participação em programas socioassistenciais), da vítima (idade na data do fato, sexo, relacionamento com o ofensor) e sobre a ofensa sexual (se praticada individualmente ou coletivamente; se intrafamiliar ou extrafamiliar).

\section{PROCEDIMENTOS}

Finalizada a etapa inicial de identificação dos adolescentes, o estudo detalhado dos processos (geralmente contendo boletim de ocorrência, folha de passagens criminais, autos de apreensão, despachos e sentenças do juiz, relatórios técnicos, dentre outros) ocorreu em salas disponibilizadas pelas VIJ e VRAIJ nos próprios órgãos, durante os meses de setembro de 2017 a junho de 2018. Nos casos em que o adolescente recebeu como sentença alguma medida socioeducativa, também foi realizado estudo do processo na VEMSE. Essa etapa final de análise documental dos processos na VEMSE aconteceu entre os meses de junho a agosto de 2018, no espaço próprio da instituição. As informações de interesse foram registradas manualmente pelos autores em instrumento específico. Posteriormente todas as informações foram organizadas em um banco de dados, sendo as análises estatísticas de frequência efetuadas através do programa de informática IBM SPSS Statistics, versão 24.

\section{CUIDADOS ÉTICOS}

A pesquisa foi antecipadamente autorizada pelos juízes da Vara da Infância e Juventude, Vara Regional de Atos Infracionais da Infância e Juventude e Vara de Execução das Medidas Socioeducativas do DF, bem como foi aprovado pelo Comitê de Ética do Instituto de Ciências Humanas da Universidade de Brasília, conforme parecer no 2.054.880. 


\section{RESULTADOS}

Este artigo apresenta especialmente as informações relativas ao processo judicial e à responsabilização do adolescente. Na Tabela 1 é possível visualizar a quantidade de processos abertos por ano, conforme data da denúncia.

Tabela 1.

Número de processos abertos conforme ano da denúncia.

\begin{tabular}{c|c|c} 
Ano & $n$ & Percentual (\%) \\
2013 & 64 & 28,7 \\
2014 & 79 & 35,4 \\
2015 & 80 & 35,9 \\
Total & 223 & 100 \\
\hline
\end{tabular}

A maior parte das denúncias referia-se a Estupro de vulnerável (79,8\%), seguido de Estupro (11,7\%). Os demais casos foram investigados como estupro/estupro de vulnerável cumulado com outros atos infracionais como ameaça, injúria, lesão corporal, furto, roubo, posse ou tráfico de drogas e tentativa de homicídio.

A Tabela 2 apresenta o tempo decorrido entre a data de revelação do fato e a data da denúncia aos órgãos competentes, bem como o tempo entre a data da denúncia e a data da sentença por parte da Justiça.

Tabela 2.

Tempo decorrido entre revelação, denúncia e sentença.

\begin{tabular}{lcc} 
Tempo & $n$ & Percentual (\%) \\
24 horas & $78(35,0)$ & $03(1,3)$ \\
24 horas a 06 meses & $96(43 \%)$ & $38(17 \%)$ \\
06 meses a 01 ano & $13(5,8)$ & $52(23,3)$ \\
01 a 02 anos & $09(4,0)$ & $92(41,3)$ \\
02 a 03 anos & 00 & $31(13,9)$ \\
Mais de 03 anos & $03(1,3)$ & $07(3,1)$ \\
Não informado & $24(10,8)$ & 00 \\
Total de processos & $223(100)$ & $223(100)$ \\
\hline
\end{tabular}

Quanto à resposta do Estado frente à ofensa sexual cometida pelo adolescente, a Tabela 3 apresenta as sentenças dadas pelos Juízes, enquanto decisão terminativa 
do processo, possibilitando a identificação das medidas socioeducativas mais aplicadas.

\section{Tabela 3.}

Sentenças recebidas pelos adolescentes.

\begin{tabular}{l|c|c|c|c} 
& \multicolumn{2}{|c|}{ Com remissão } & \multicolumn{2}{c}{ Total } \\
\cline { 2 - 5 } Sentença & Sim $(n)$ & Não $(n)$ & $n$ & $\%$ \\
Absolvido/ Improcedente & - & - & 08 & 3,2 \\
Arquivamento & - & - & 101 & 39,9 \\
Extinção do processo & - & - & 01 & 0,4 \\
Somente remissão & 54 & - & 54 & 21,3 \\
Advertência & 01 & 02 & 03 & 1,2 \\
Advertência + PSC & 08 & 01 & 09 & 3,6 \\
Advertência + LA & 06 & 00 & 06 & 2,4 \\
Advertência + LA + PSC & 01 & 00 & 01 & 0,4 \\
PSC & 19 & 02 & 21 & 8,3 \\
PSC + LA & 04 & 06 & 10 & 4,0 \\
LA & 27 & 06 & 33 & 13,0 \\
Semiliberdade & 00 & 00 & 00 & 00 \\
Internação & 00 & 06 & 06 & 2,4 \\
Total de adolescentes & 120 & 23 & 253 & 100 \\
\hline
\end{tabular}

Dos 253 adolescentes participantes da pesquisa, é possível identificar na Tabela 3 que 89 deles receberam medida socioeducativa (35,3\%), ou seja, receberam como sentença advertência $(n=3)$, advertência com PSC $(n=09)$, advertência com LA $(n=06)$, advertência com LA e PSC $(n=01)$, PSC $(n=21)$, PSC com LA $(n=10)$, LA $(n=33)$ e internação $(n=06)$. Aqueles que receberam somente advertência tiveram a medida decretada cumprida no mesmo momento da sentença.

Pode-se observar ainda na Tabela 3, adolescentes que receberam somente a remissão $(n=54)$ e adolescentes que receberam a medida socioeducativa com ou sem remissão judicial. Ao todo foram 66 adolescentes que receberam medida socioeducativa cumulada com a remissão judicial, conforme previsto no artigo 127 do ECA. Destacam-se as medidas socioeducativas de PSC (19 adolescentes receberam a PSC cumulada com a remissão e 02 receberam a PSC sem a remissão) e a LA (27 adolescentes receberam a LA cumulada com a remissão e 06 receberam a LA sem remissão). 
Já a Tabela 4 apresenta o número de adolescentes que receberam alguma medida protetiva, independente da medida socioeducativa.

\section{Tabela 4.}

Número de adolescentes que receberam medida protetiva.

\begin{tabular}{l|c|c} 
Medida Protetiva & $n$ & $\%$ \\
$\begin{array}{l}\text { Não receberam MP } \\
\text { Receberam MP }\end{array}$ & 235 & 92,9 \\
$\quad \begin{array}{l}\text { Requisição de tratamento médico, psicológico ou } \\
\text { psiquiátrico, em regime hospitalar ou ambulatorial }\end{array}$ & 11 & 4,3 \\
$\begin{array}{l}\text { Orientação, apoio e acompanhamento temporários } \\
\text { Inclusão em programa oficial comunitário de } \\
\text { auxílio, orientação e tratamento a alcoólatras e } \\
\text { toxicômanos }\end{array}$ & 03 & 1,2 \\
$\quad \begin{array}{l}\text { Matrícula e frequência obrigatórias em } \\
\text { estabelecimento oficial de ensino fundamental }\end{array}$ & 01 & 0,8 \\
$\begin{array}{l}\text { Requisição de tratamento médico, psicológico ou } \\
\text { psiquiátrico, em regime hospitalar ou ambulatorial } \\
\text { e inclusão em programa oficial comunitário de } \\
\text { auxílio, orientação e tratamento a alcoólatras e } \\
\text { toxicômanos }\end{array}$ & 01 & 0,4 \\
\begin{tabular}{l} 
Total de adolescentes \\
\hline
\end{tabular} & & 100 \\
\hline
\end{tabular}

A Tabela 5 apresenta a situação dos adolescentes em relação ao cumprimento da medida socioeducativa, até a finalização da pesquisa documental.

Tabela 5.

\section{Situação dos adolescentes que receberam Medida Socioeducativa (MSE)}

\begin{tabular}{lc|c} 
Situação final & $n$ & $\%$ \\
Concluiu a MSE & 58 & 67,5 \\
Não concluiu a MSE & 15 & 17,5 \\
Em andamento & 03 & 3,5 \\
Não iniciada a MSE & 01 & 1,1 \\
Processo não localizado & 05 & 5,8 \\
Processo transferido para outra & 04 & 4,6 \\
comarca $^{\text {Total }}{ }^{1}$ & & \\
\hline
\end{tabular}

\footnotetext{
${ }^{1}$ Total de adolescentes que receberam medidas socioeducativas, exceto advertência.
} 


\section{DISCUSSÃO}

Dos 223 processos estudados, observou-se um aumento do número de processos abertos entre os anos de 2013 e 2015, o que alinha com o aumento das notificações pelo SINAN e dos registros de violência sexual feitos nas delegacias nos últimos anos (IPEA, 2018). Esse incremento pode estar atrelado a maior visibilidade dada à violência sexual e aos avanços significativos do país em relação ao enfrentamento dessa problemática (Secretaria Nacional de Direitos Humanos, 2013).

O momento da revelação do abuso, quando a vítima conta para alguém de confiança sobre a violência que sofreu ou vem sofrendo, é considerado decisivo. É o momento em que o segredo vem à tona e, a partir dessa revelação, decorrem os mais diversos efeitos, tanto para as vítimas, como para os familiares e ofensores, principalmente quando a ofensa é praticada por alguém próximo e de confiança. Ao estudar o período entre a revelação e o atendimento às famílias em situação de abuso sexual, Marra e Costa (2018) relatam que, à medida que a narrativa das vítimas se torna pública, surgem desdobramentos diversos na família, inclusive acirramento dos conflitos já existentes antes da revelação da violência. $\mathrm{Na}$ presente pesquisa, em $43 \%$ dos processos, a denúncia às autoridades competentes foi realizada em até seis meses após a revelação do fato, seguido de $35 \%$ dos casos em que a denúncia foi realizada nas 24 horas após a ocorrência do fato. Considerando o vínculo existente com a vítima, as famílias têm mais dificuldade de denunciar a violência quando o ofensor é alguém da família. Tais informações são significativas e demonstram a importância de um atendimento qualificado às famílias. Segundo Marra e Costa (2018), quando esse atendimento é realizado num contínuo à revelação, as ações de cuidado e vigilância são fortalecidas, impedindo que as crianças sofram novos abusos de pessoas de seu convívio.

Autores indicam que a revelação propriamente dita por parte da vítima, em especial crianças e adolescentes, é resultado da interação de diversos fatores e constitui um processo que envolve as características individuais da vítima, a relação com a pessoa de confiança, que poderá ou não ter disponibilidade para escutar e reagir, o contexto e o momento escolhido pela vítima para revelar (Padilha \& Filho, 2016; Santos \& Dell'Aglio, 2013). Outro aspecto refere-se à denúncia às autoridades competentes, relacionado ao desconhecimento das famílias em relação às instituições que acolhem as denúncias, bem como às dificuldades dos profissionais, sejam de saúde ou do judiciário, de lidarem com a questão, especialmente quando o ofensor se trata de outro adolescente (Domingues, 2016). No estudo realizado por Costa (2011) com famílias de adolescentes ofensores sexuais, observou-se que as famílias têm muito receio de irem à delegacia denunciar a ofensa sexual, sendo a principal queixa o medo de maus-tratos por parte dos policiais e as acusações de negligência. Assim, percebe-se que as famílias têm dificuldades de procurar espontaneamente 0 Sistema de Justiça para denunciar, seja a Delegacia ou mesmo o Conselho 
Tutelar. Outro fator importante diz respeito às dificuldades das famílias perceberem e definirem como violência situações cotidianas e que são encaradas como atos rotineiros. Com isso, a passagem da família pelo contexto jurídico e o processo de responsabilização do adolescente ofensor sexual, em caso de comprovação da conduta infracional, tornam-se uma oportunidade para a ressignificação da violência enquanto violência.

Superada a barreira relativa à denúncia, cabe a Justiça apurar e se for o caso, responsabilizar o ofensor. Na presente pesquisa, observou-se uma grande variação com relação ao período total de apuração do ato infracional e conclusão do processo. Um número significativo de casos (41,3\%) demorou entre um e dois anos para receber uma resposta do Sistema de Justiça, seguido de 23,3\% com tempo de apuração entre 06 meses e 01 ano. No entanto, há casos em que a Justiça demorou 02 anos ou mais para concluir a apuração do ato infracional. Tendo em vista a idade do adolescente e as implicações pessoais, familiares e sociais decorrentes da prática da ofensa sexual, esse tempo é excessivo considerando a urgência do atendimento que a situação requer.

A adolescência compõe a transição entre a infância e a vida adulta e é marcada por muitas mudanças (Carreteiro, 2010). Considerando a idade que compreende a adolescência, entre 12 e 18 anos incompletos (Eisenstein, 2005) e a condição peculiar do adolescente como pessoa em desenvolvimento, não restam dúvidas da importância da agilidade e celeridade na apuração dos atos infracionais, visando uma intervenção que vai além dos aspectos sancionatórios e que seja realmente efetiva. De um lado, o artigo 100, inciso VI e artigo 113 do ECA, estabelecem a "intervenção precoce" como princípio na aplicação das medidas protetivas e socioeducativas. Nesse sentido, logo que a situação de perigo seja reconhecida, o processo de apuração deve transcorrer no menor período de tempo possível, de forma ágil, a fim de intervir de forma realmente socioeducativa e cessar a violência. De outro lado, a celeridade processual não pode sobrepor aos direitos individuais e às garantias processuais do adolescente, estabelecidas nos artigos 106 e 111 do ECA (Andrade \& Machado, 2017).

Estudos sobre os adolescentes que cometeram abuso sexual (Barroso, 2012; Nogueira-da Silva \& Costa, 2013) revelam que a organização dessas famílias se volta especialmente para a manutenção das necessidades básicas, com distribuição de tarefas e responsabilidades entre os seus membros, ficando o adolescente ofensor, na maioria das vezes, responsável pelo cuidado da casa e dos irmãos enquanto os pais trabalham fora. Além disso, são adolescentes que possuem apoio familiar e social restrito, uma vez que não convivem com outros parentes distantes e não fazem uso dos recursos sociais da comunidade. Geralmente apresentam mais história de abuso sexual, abuso físico e negligência, assim como exposição precoce a sexo e pornografia.

Nesse cenário, também é importante que o Sistema de Justiça considere ao longo da apuração do processo, e consequentemente nas suas decisões, que 
essas famílias tiveram seus direitos violados pela impossibilidade de usufruir das necessidades fundamentais como: alimentação, educação, saúde, habitação, segurança, cultura e lazer, dentre outras. É uma problemática que evidencia o direito como um complexo carregado de contradições, cujas necessidades apresentadas por sujeitos singulares não podem ser compreendidas somente como problemas individuais. Ao contrário, são demandas decorrentes da desigualdade social própria da organização da sociedade atual, de negação e não universalização dos direitos (CFESS, 2013). Por isso, a importância de uma atuação do Sistema de Justiça que seja diferente da reprodução da ordem já existente e impulsione ações mais emancipatórias e garantidoras também dos direitos sociais.

Dos resultados dos processos, apenas 3,2\% dos adolescentes foram absolvidos ou tiveram o caso julgado como improcedente. Um número significativo de adolescentes (40,3\%) teve o processo arquivado ou extinto. As motivações para o arquivamento foram diversas, dentre elas: a falta de evidências ou de indícios que comprovassem o fato; dificuldade de encontrar o adolescente ofensor para oitiva; morte do ofensor; suspeita de alienação parental; adolescente maior de 21 anos ou já respondendo ou cumprindo medida socioeducativa/pena por outro ato infracional/crime; ausência de justa causa para aplicação de medida socioeducativa; bem como a "perda da pretensão socioeducativa" devido ao grande "lapso temporal" entre a data do fato e a sentença. Tais motivações estavam explícitas em algumas sentenças e foram identificadas ao longo da pesquisa documental.

Sabe-se que as ofensas sexuais são consideradas "crimes" silenciosos, na maioria das vezes sem testemunhas, e que, por isso, apresentam uma série de dificuldades para sua investigação. Segundo Benia (2005), como a denúncia da violência sofrida não é imediata, mas realizada geralmente após um longo período de tempo, em grande parte dos casos não há evidências em exames físicos, sendo o depoimento da criança a única e principal evidência do abuso, pelo qual poderá ser avaliado e validado. Essa mesma lógica de depoimento se aplica aos casos de crianças e adolescentes vítimas de ofensa sexual praticada por adolescentes. Sem adentrar nas questões legais, doutrinárias e jurisprudenciais relativas à "prescrição" da medida socioeducativa, tal fato evidencia ainda mais a importância da celeridade na apuração do ato infracional, seja ele de natureza sexual ou não. Com a demora, a resposta estatal diante da prática de um ato infracional corre o risco de perder seu caráter educativo, assumindo um caráter meramente punitivo. Ao mesmo tempo, considerando a alta incidência dos casos de violência sexual, a gravidade das consequências nas vítimas e a clara necessidade de interrupção do ciclo vitimização - agressão, a justiça se torna leniente ao responsabilizar os adolescentes ofensores sexuais.

Dentre as medidas socioeducativas aplicadas nos processos analisados, há uma prevalência das medidas socioeducativas de meio aberto. Apenas 2,4\% dos adolescentes tiveram medida restritiva de liberdade. No entanto, percebeu-se 
uma grande margem de discricionariedade em relação à aplicação da medida socioeducativa, conforme apontado por Andrade e Machado (2017), considerando a falta de critérios claros na aplicação de uma medida socioeducativa em detrimento da outra. Os estudos de Domingues e Costa (2017) ressaltam que os documentos constantes nos processos judiciais carecem de informações a respeito do adolescente ofensor sexual, o que dificulta uma tomada de decisão por parte do juiz. História pregressa, situação socioeconômica, relação com familiares e redes sociais, são praticamente inexistentes, de forma que são levadas em conta principalmente informações sobre a vítima. Tal situação também foi observada na presente pesquisa.

É certo que, assim como em outras profissões, a imparcialidade é sempre questionável. É impossível dissociar o saber e fazer profissional das convicções pessoais, das trajetórias de vida e experiências vividas. Sena e Penso (2019), ao tratar da guarda compartilhada em entrevistas com juízes da Vara de Família, observaram como as vivências pessoais construíram e constroem a lente que os juízes usam em sua atuação com as famílias. Também nos casos das decisões sobre a responsabilização do adolescente autor de ato infracional, apesar de todo aparato de leis e instrumentos que formam o saber do magistrado, suas impressões acerca da família, da adolescência, da parentalidade, das concepções de gênero e de sexualidade são revisitadas e exercem influência no processo decisório. Nessa linha, também Minahim (2010) identifica a presença de aspectos morais e juízos de valor nas decisões judiciais estudadas, além de visões estereotipadas dos adolescentes.

Ainda relacionado à discricionariedade dos juízes, merece destaque a grande quantidade de processos cujos adolescentes receberam ao mesmo tempo e numa mesma sentença a remissão e a medida socioeducativa. Dos 89 adolescentes que tiveram como sentença a aplicação de medida socioeducativa, 66 deles receberam medida socioeducativa e a remissão juntas. Conforme artigo 127 do ECA, "a remissão não implica necessariamente o reconhecimento ou comprovação da responsabilidade, nem prevalece para efeito de antecedentes, podendo incluir eventualmente a aplicação de qualquer das medidas previstas em lei, exceto a colocação em regime de semiliberdade e internação". Para Silva (2003), a remissão foi uma inovação introduzida pelo ECA e tem sido entendida como o "perdão" concedido ao adolescente acusado de ato infracional, com vistas à exclusão, suspensão ou extinção do processo, protegendo o adolescente dos efeitos negativos e prejudiciais acarretados pelo procedimento judicial e "desafogando a máquina judiciária". No entanto, Andrade e Machado (2017) apontam que existe um equívoco da lei ao disciplinar o instituto da remissão da forma como está, uma vez que a conotação de perdão, especialmente com a aplicação da medida socioeducativa, perde o sentido. Estes autores relatam que a prática das Varas da Infância e Juventude é conceder a remissão várias vezes a um mesmo adolescente ou mesmo na ausência de um advogado, distorcendo a utilização do dispositivo. Além disso, o judiciário não pode homologar uma remissão acompanhada por medida socioeducativa proposta pelo Ministério 
Público, sem que o adolescente, orientado por um advogado e acompanhado de um responsável, concorde com a sujeição negociada (Andrade \& Machado, 2017). Tal dispositivo pode contribuir com a celeridade do processo, no entanto, ao "perdoar" e "punir", a justiça impede que a violência seja reconhecida enquanto tal, além de prejudicar as garantias processuais e dificultar o cumprimento da medida imposta. Uma vez que não houve o reconhecimento da culpa e da responsabilidade pelo ato praticado, o adolescente pode não se sentir no "dever" de cumprir as obrigações que lhe foram impostas mediante a aplicação da medida socioeducativa.

Outro aspecto que chama a atenção diz respeito à aplicação de medidas protetivas. Dos 253 adolescentes identificados, apenas 7,1\% ( $n=18)$ tinham registrado no processo judicial a aplicação de alguma medida protetiva. Além de responsabilizados, os adolescentes ofensores sexuais precisam ser protegidos. Assim, é importante que as medidas socioeducativas estejam associadas a uma medida protetiva, que lhes "garanta condições para continuarem seu processo de desenvolvimento e construção de suas identidades" (Costa, Penso, \& Chaves, 2017, p.127). A medida protetiva favorece o acesso dos adolescentes e familiares a instituições de educação, saúde, esporte, assistência social, contribuindo para a garantia de direitos que até então Ihes foram negados. Além disso, contribui para o atendimento às múltiplas experiências de vitimização que o adolescente possa ter vivido ao longo de sua trajetória de vida (Finkelhor, Ormrod, Turner, \& Hamby, 2005). Em muitos casos de ofensa sexual, a inclusão do adolescente e da família em programas de orientação, saúde e educação, por si só, contribui para a tomada de consciência quanto à lesividade de tal conduta, possibilitando uma resposta mais efetiva e não meramente punitiva à transgressão.

Outro dado significativo refere-se ao cumprimento da medida socioeducativa: $67,5 \%$ dos adolescentes conseguiram concluir a medida imposta (LA, PSC ou Internação). Novos estudos precisam ser realizados no sentido de conhecer a experiência desse adolescente ao longo do período de cumprimento, as atividades e encaminhamentos realizados e se a medida socioeducativa realmente atingiu os objetivos esperados de responsabilização e de integração social. Penso et al. (2018) afirmam que o ECA tem como proposta transformar as medidas socioeducativas numa experiência significativa na vida do adolescente. Portanto, o foco de intervenção socioeducativa, pode-se dizer a resposta dada aos adolescentes pelo ato infracional praticado, deve levar em consideração não somente o aspecto sancionatório, ou seja, o aspecto coercitivo da medida face à transgressão cometida, mas também o aspecto educativo ou reeducativo, que envolve a "reconciliação" do adolescente com a sociedade, sua volta ao convívio social em outros padrões relacionais, e o aspecto reparatório, a "reconciliação" do adolescente com ele mesmo, por meio de um processo interno de reflexão a respeito do ato infracional cometido e busca de sua identidade. Esse é grande desafio das medidas socioeducativas. 


\section{CONSIDERAÇÕES FINAIS}

Uma reflexão sobre responsabilização do adolescente ofensor sexual não pode ser descolada de uma análise histórica e política sobre a garantia/violação dos direitos da criança e do adolescente, bem como da relação entre juventude e violência na sociedade atual. Apesar dos avanços estabelecidos pelo ECA, existe uma grande lacuna entre o plano teórico do ECA e a plena efetivação dos direitos das crianças e dos adolescentes, aliando o problema do cometimento de atos infracionais à ausência de direitos fundamentais para uma grande parte da população brasileira.

Embora diversos estudos sobre o adolescente que cometeu ofensa sexual e suas relações familiares destacarem que não há um perfil único, tratando-se de um público bastante heterogêneo, há um consenso de que são adolescentes que vivem em ambientes familiares e comunitários repletos de conflitos e violências (Barroso, 2012; Butler \& Seto, 2002; McCuish, Lussier, \& Corrado, 2014; Pullman et al., 2014). Dessa forma, a responsabilização jurídica, acionada como a principal estratégia de responsabilização e com vistas a atender à necessidade de punir o adolescente aos olhos da sociedade, não pode ser a única forma de resposta do Estado frente à prática da ofensa sexual. É fundamental que a responsabilização do adolescente ofensor sexual envolva também os aspectos educativos e reparatórios, o que exige um conhecimento e intervenção interdisciplinar ao longo de todo o processo. Para Russel e Marsh (2018), percepções equivocadas sobre os adolescentes ofensores sexuais podem influenciar a tomada de decisões por parte dos juízes e podem levar a consequências não intencionais, contraditórias ou iatrogênicas. Nesse sentido, o acompanhamento e tratamento devem superar a punição.

Na presente pesquisa, observou-se que, de um lado, o Sistema de Justiça é moroso em relação à responsabilização do adolescente autor de ofensa sexual, o que não configura uma novidade. Porém, devido à especificidade da violência sexual, tal demora traz enormes prejuízos ao adolescente, à vítima e à sociedade, uma vez que o Sistema de Justiça representa uma oportunidade para a ressignificação da violência enquanto violência, seja por parte do adolescente, como de sua família. E, muitas vezes, a única oportunidade para isso, considerando que os adolescentes e familiares que chegam às Varas da Infância e Juventude, especialmente os autores de ato infracional, têm uma história na qual os direitos fundamentais lhes foram negados ao longo da vida. De outro, a prevalência das medidas socioeducativas de meio aberto é um aspecto positivo, pois pode demonstrar a crença numa alternativa potencialmente mais educativa (Frasseto et al., 2012).

Por fim, pode-se dizer que a proposta do SINASE sinaliza uma corresponsabilização, meta a ser perseguida por todos os operadores do sistema socioeducativo, uma vez que dá ênfase à participação da comunidade e da família no processo de responsabilização do adolescente. Valente e Oliveira 
(2015) destacam a importância de entender que o ato infracional não inicia nem termina no adolescente, sendo fundamental reconhecer a responsabilidade de outras esferas sociais no complexo processo que fez do adolescente um "infrator", bem como no processo que pode favorecer a mudança de sua trajetória de vida.

\section{REFERÊNCIAS}

Andrade, A. P., \& Machado, B. A. (2017). Justiça e Processo Penal Juvenil: Paradigmas discurso jurídico e o modelo brasileiro. In A. P. Andrade \& B. A. Machado (Eds.), Justiça Juvenil: Paradigmas e experiências comparadas (pp. 23-56). São Paulo, SP: Marcial Pons.

Barroso, R. N. S. G. (2012). Características e especificidades de jovens agressores sexuais (Tese de doutorado). Universidade de Aveiro, Minho.

Benia, L. R. (2015). A entrevista de crianças com suspeita de abuso sexual. Estudos de Psicologia, 32(1), 27-35. https://doi.org/10.1590/0103-166X2015000100003

Butler, S. M., \& Seto, M. C (2002). Distinguishing two types of adolescent sex offenders. American Academy of Child Psychiatry, 41(1), 83-90. doi:10.1097/00004583-200201000-00015

Carreteiro, T. (2010). Adolescências e experimentações possíveis. In M. M. Marra \& L. F. Costa (Eds.), Temas da clínica do adolescente e familia (pp.15-24). São Paulo, SP: Ágora.

Conselho Federal de Serviço Social (2013). Atuação de assistentes sociais no sociojurídico. Subsídios para a reflexão. Brasília, DF: CFESS.

Costa, L. F. (2011). Participação de famílias no grupo multifamiliar de adolescentes ofensores sexuais: Vergonha e confiança. Psicologia Clínica, 23(1), 185-201.

Costa, L. F., Penso, M. A., \& Chaves, M. N.G. (2017). Violência e história de vida do adolescente que cometeu ato infracional de natureza sexual. In A. P. Andrade \& B. A. Machado (Eds.), Justiça juvenil: Paradigmas e experiências comparadas (pp. 23-56). São Paulo, SP: Marcial Pons.

Costa, L. F., \& Santos, V.A. (2013). A natureza paradoxal das medidas protetivas em casos de violência sexual intrafamiliar. Revista de Direito da Infância e da Juventude, 1(1), 281-300.

Domingues, D. F. (2016). Adolescentes em situação de ofensa sexual intrafamiliar: Conhecer e intervir para prevenir a reincidência (Tese de Doutorado). Universidade de Brasília, Brasília.

Domingues, D. F., \& Costa, L. F. (2017). Adolescentes que cometeram ofensa sexual: Análise documental em processos judiciais. Pensando Famílias, 21(2), 15-27.

Eisenstein, E. (2005). Adolescência: Definições, conceitos e critérios. Revista Adolescência \& Saúde, 2(2), 6-7.

Fávero, E. T. (2013). Serviço Social no Judiciário: Construções e desafios com base na realidade paulista. Serviço Social e Sociedade, 115, 508-526. doi:10.1590/S0101-66282013000300006

Finkelhor, D., Ormrod, R. K., Turner, H. A., \& Hamby, S. L. (2005). Measuring poly-victimization using the Juvenile Victimization Questionnaire. Child Abuse \& Neglect, 29, 1297-1312. doi:10.1016/j.chiabu.2005.06.005

Frasseto, F. A., Guará, I. M. F. R., Botarellii, A., \& Barone, R. E. M. (2012). Gênese e Desdobramentos da Lei 12594-2012: Reflexos na ação socioeducativa. Revista Brasileira Adolescência e Conflitualidade, 6, 19-72.

Instituto de Pesquisas Econômicas e Aplicadas (2018). Atlas da violência. Disponível em http://www.ipea.gov.br/portal/index.php?option=com_content\&view=article\&id=33410\&It emid $=432$

Marra, M. M., \& Costa, L. F. (2018). Entre a revelação e o atendimento: Família e abuso sexual. Avances in Psicologia Latinoamericana, 36(3), 459-475. http://dx.doi.org/10.12804/revistas.urosario.edu.co/apl/a.3564

McCuish, E. C., Lussier, P., \& Corrado, R. R. (2014). Examining antisocial behavioral antecedents of juvenile sexual offenders and juvenile non-sexual offenders. Sexual Abuse: A Journal of Research and Treatment, 274), 414-438. doi:10.1177/1079063213517268

Mendez, E. G. (2000). Adolescentes e responsabilidade penal: Um debate Latino-Americano. Cuadernos de doctrina y jurisprudenica penal, 4(10), 261-275.

Minahim, M. A. (2010). ECA: apuração do ato infracional atribuído a adolescentes. Série Pensando o Direito. Brasília, DF: Ministério da Justiça - UFBA. 
Ministério dos Direitos Humanos (2018). Levantamento Anual do SINASE 2016. Brasília, DF: Secretaria Nacional dos Direitos da Criança e do Adolescente.

Ministério da Justiça e Segurança Pública (2017). Levantamento Nacional de Informações Penitenciárias: INFOPEN. Brasília, DF: Ministério da Justiça e Segurança Pública.

Ministério da Saúde (2018). Análise epidemiológica da violência sexual contra crianças e adolescentes no Brasil, 2011 a 2017. Boletim Epidemiológico do Ministério da Saúde, 49(27). Disponível

em https://portalarquivos2.saude.gov.br/images/pdf/2018/junho/25/2018-024.pdf

Nogueira-da Silva Costa, B., \& Costa, L. F. (2013). The sexual offender teenager, both perpetrator and victim. Revista Latinoamericana de Ciencias Sociales, Niñez y Juventud, 11(2), 633-645. doi:10.11600/1692715x.11212180213

Padilha, M. G. S., \& Filho, I. X. V. (2016). Abuso sexual: A violência sexual contra vulneráveis. In P. I. Gomide \& S. S. Staut Júnior (Eds.), Introdução à Psicologia Forense (pp. 183-204), Curitiba, PR: Juruá.

Penso, M. A., Conceição, M. I. G., Costa, L. F., \& Carreteiro, T. C. O. (2012). Jovens pedem socorro. O adolescente que praticou ato infracional e o adolescente que cometeu ofensa sexual. Brasília, DF: Liber Livro.

Penso, M. A., Conceição, M. I. G., \& Costa, L. F. (2018). Revisão histórica da Psicologia Jurídica na atenção à família e ao sujeito. In L. F. Habigzang, P. I. Gomide, \& G. M. Rocha (Eds.), Psicologia Forense. Temas e Práticas (p.19-37). Curitiba, PR: Juruá.

Pincolini, A. M. F., \& Hutz, C. S. (2014). Abusadores sexuais adultos e adolescentes no sul do Brasil: Pesquisa em denúncias e sentenças judiciais. Temas Em Psicologia, 22(2), 301-311. doi:10.9788/TP2014.2-03

Presidência da República. Casa Civil. Subchefia para Assuntos Jurídicos (1990). Lei n 8069, de 13 de julho de 1990. Dispõe sobre o Estatuto da Criança e do Adolescente e dá outras providências. Diário Oficial da União, Brasília, DF. Disponível em http://www.planalto.gov.br/ccivil_03/leis/18069.htm

Presidência da República. Casa Civil. Subchefia para Assuntos Jurídicos (2009). Lei n 12.015, de 07 de agosto de 2009. Altera o Título VI da Parte Especial do Decreto-Lei no. 2.848, de 7 de dezembro de 1940 (Código Penal), e o art. 1o. da Lei no. 8.072, de 25 de julho de 1990. Diário Oficial da União, Brasília, DF. Disponível em http://www.planalto.gov.br/ccivil_03/_Ato2007-2010/2009/Lei/L12015.htm

Presidência da República. Casa Civil. Subchefia para Assuntos Jurídicos (2012). Lei no 12.594 de 18 de janeiro de 2012. Institui o Sistema Nacional de Atendimento (SINASE), regulamenta a execução das medidas socioeducativas destinadas a adolescente que pratique ato infracional e altera as leis nos. 8.069, de 13 de julho de 1990; 7.560, de 19 de dezembro de 1986; 7.998 de 11 de janeiro de 1990; 5.537, de 21 de novembro de 1986; 8.315, de 23 de dezembro de 1991; 8.706 de 14 de setembro de 1993; os decretos-leis nos. 4.048, de 22 de janeiro de 1942; 8.621 de 10 de janeiro de 1946; e a Consolidação das Leis do Trabalho (CLT), aprovada pelo Decreto-lei no. 5.452, de $1^{\circ}$. De maio de 1943. Diário Oficial da União, Brasília, DF. Disponível em http://www.planalto.gov.br/ccivil_03/_Ato20112014/2012/Lei/L12594.htm

Presidência da República. Secretaria-geral. Subchefia para Assuntos Jurídicos (2018). Lei n. 13.718 de 24 de setembro de 2018. (2018, 25 de setembro). Altera o Decreto-Lei no 2.848, de 7 de dezembro de 1940 (Código Penal) e revoga dispositivo do Decreto-Lei no. 3.688 de 3 de outubro de 1941 (Lei das Contravenções Penais). Diário Oficial da União, Brasília, DF. Disponível em http://www.planalto.gov.br/ccivil_03/_ato2015-2018/2018/lei/L13718.htm

Pullman, L. E., Leroux, E. J., Motayne, G., \& Seto, M. C. (2014). Examining the developmental trajectories of adolescent sexual offenders. Child Abuse \& Neglect, 38(7), 1249-1258. doi:10.1016/j.chiabu.2014.03.003

Pullman, L., \& Seto, M. C. (2012). Assessment and treatment of adolescent sexual offenders: Implications of recent research on generalist versus specialist explanations. Child Abuse and Neglect, 36(3), 203-209. doi:10.1016/j.chiabu.2014.03.003

Russel, N. K., \& Marsh, S. C. (2018). When juveniles commit sexual offenses: Considerations and recommendations for judges. Juvenile and Family Court Journal, 69(2), 37-48.

Santos, S. S. dos, \& Dell'Aglio, D. D. (2013). O processo de revelação do abuso sexual na percepção de mães. Revista Psicologia: Teoria e Prática, 15(1), 50-64. 
Saraiva, J. B. C. (2017). O direito penal para adolescentes: Um rápido panorama dos direitos humanos especiais destes sujeitos em peculiar condição de desenvolvimento em nosso continente e no Brasil. In A. P. Andrade \& B. A. Machado (Eds.), Justiça juvenil: Paradigmas e experiências comparadas (pp. 23-56). São Paulo, SP: Marcial Pons.

Secretaria Nacional de Direitos Humanos (2013). Plano nacional de enfrentamento da violência sexual contra crianças e adolescentes. Brasília, DF: Secretaria Nacional de Direitos Humanos. Disponível

em http://www.crianca.mppr.mp.br/arquivos/File/publi/sedh/08_2013_pnevsca.pdf

Sena, D., \& Penso, M. A. (2019). Os juízes de família e a guarda compartilhada: Uma análise psicojurídica. Jundiaí, SP: Paco.

Silva, R. B. D. (2003). Remissão para exclusão do processo como direito dos adolescentes: Uma interpretação conforme a constituição. Porto Alegre, RS: Sérgio Antonio Fabris Editor.

Tribunal de Justiça do Distrito Federal e Territórios (2020). História. Disponível em https://www.tjdft.jus.br/informacoes/infancia-e-juventude/institucional/historia

Valente, F. P. R., \& Oliveira, M. C. S. L. (2015). Para além da punição: (Re)construindo o conceito de responsabilização socioeducativa. Estudos e Pesquisa em Psicologia, 15(3), 853-870. doi:10.12957/epp.2015.19416

Yeater, E. A., Lenberg, K. L., \& Bryan, A. D. (2012). Predictors of sexual aggression among male juvenile offenders. Journal of Interpersonal Violence, 27, 1242-1258. doi:10.1177/0886260511425243

World Health Organization (2002). World report on violence and health: summary. Geneva. Disponível

em https://www.who.int/violence_injury_prevention/violence/world_report/en/

Worling, J. R., \& Langton, C. M. (2015). A prospective investigation of factors that predict desistence from recidivism for adolescents who have sexually offended. Sexual Abuse: A journal of research and treatment, 27(1), 127-142. doi:10.1177/1079063214549260

\section{AGRADECIMENTOS}

As autoras agradecem à Vara da Infância e Juventude, à Vara Regional de Atos Infracionais da Infância e da Juventude e à Vara de Execução das Medidas Socieducativas do Distrito Federal, pelo apoio na coleta de dados e disponibilização dos processos.

\section{DECLARAÇÃO DE CONFLTTOS DE INTERESSE}

Não há conflitos de interesse.

\section{SOBRE AS AUTORAS}

Kárita Rachel P. Bastos é assistente social da Subsecretaria do Sistema Socioeducativo, vinculada à Secretaria de Estado de Justiça e Cidadania do Distrito Federal. Mestre em Serviço Social pela Pontifícia Universidade de São Paulo e Doutora pela Universidade de Brasília.

E-mail: krbastos@gmail.com

(1)https://orcid.org/0000-0002-7314-4553

Liana Fortunato Costa é psicóloga, Doutora em Psicologia Clínica pela Universidade de São Paulo, Pós-doutora em História de Vida pela Universidade Federal Fluminense. Docente Permanente do Programa de Pós-Graduação em Psicologia Clínica e Cultura da Universidade de Brasília.

E-mail: lianaf@terra.com.br

(1) http://orcid.org/0000-0002-7473-1362 